\title{
Integration of Management Systems: The Views of Contractors
}

\author{
S.X. Zeng ${ }^{* \dagger}$, G.X. Lou* \&** and Vivian W.Y. Tam ${ }^{* *}$
}

\author{
*Aetna School of Management, Shanghai Jiaotong University, Shanghai 200052, China \\ ** School of Business and Economics, East China University of Science and Technology, Shanghai, China \\ *** School of Engineering, Gold Coast Campus, Griffith University PMB50, Gold Coast Mail Centre, Qld 9726, Australia \\ ${ }^{\dagger}$ Corresponding author: Tel: 86-21-5230 2563; Fax: 86-21-6293 2577; Email: zengsaixing@ sjtu.edu.cn
}

Received 27 April 2005; accepted 10 October 2005; final revisions 2 August 2006

\begin{abstract}
As most international contractors are implementing the international standards of ISO 9001, ISO 14001 and OHSAS 18001 in their organizations, they have realized many challenges and difficulties during implementation. An integrated management system (IMS) in combining ISO 9001, ISO 14001 and OHSAS 18001 provides a possible solution in effectively and efficiently managing these international requirements. Supported by a structured questionnaire survey, this paper examines the implementation of IMS in the China construction industry. The results revealed that the majority of the firms supported the integration of the quality (ISO 9001), environmental (ISO 14001) and occupational health and safety (OHSAS 18001) management systems. In implementing IMS, the internal barriers include: (1) human resources; (2) organizational structure; (3) company culture; and (4) understanding and perception; and the external barriers include: (1) technical guidance; (2) certifying bodies; (3) stakeholders and customers; and (4) the institutional environment. The research also suggests and recommends some approaches to complete the integration.
\end{abstract}

Keywords: Contractors; Environment; Health \& safety; Integrated management systems; Quality assurance

\section{Introduction}

In recent years, the ISO 9001 (quality), ISO 14001 (environmental) and OHSAS 18001 (occupational health and safety) standards have been extensively adopted worldwide (Pun and Hui, 2002). ISO 9001 is geared towards customer satisfaction; ISO 14001 aims at supporting environmental protection and pollution prevention management while promoting a social and economic harmony; and OHSAS 18001 is directed at the pro-active control of occupational risk enabling the organization to improve its health and safety related performance (Matias and Coelho, 2002).

Obviously these standards share similar management techniques and principles. They require organizations to formulate policies, to define roles and responsibilities, to appoint management representatives and to train personnel (Bamber et al., 2004). Implementation of ISO 9001, ISO 14001 and OHSAS 18001 demands many duplicate management tasks. For example, these standards require all working procedures to be traceable and auditable. Therefore, three separate documentation systems are needed to meet their requirements, which involve complicated documentation, written procedures, checking, control forms and other paper work. It has been proved difficult to deal with separate management systems covering quality, environment and occupational health and safety, and ensuring that they align with the organizational strategy (Wilkinson \& Dale, 1998). Under this circumstance, integrated management system (IMS) has drawn the attentions to both academics and practitioners. An IMS is increasingly seen as a part of the organizational management portfolio.

At a worldwide level, the construction industry has the third highest number of ISO 9000 certificates among all industrial sectors (Chini \& Valdez, 2003). At the same time, an increasing number of construction organizations are planning to implement ISO 14001 and OHSAS 18001 (Low \& Chin, 2003; Zeng et al., 2003).

Although it is theoretically feasible to integrate ISO 9001, ISO 14001 and OHSAS 18001 in terms of documentation, it is unclear on the attitude of contractors toward such integration. This paper intends to present relevant information obtained from a structured questionnaire survey for continuous improvement in integrating the management systems. The following objectives are focus on:

- To examine the attitude of contractors towards integrated management system;

- To investigate the barriers of implementing integrated management system;

- To analyze the approaches in implementing integrated management system; and 
- To explore several suggestions and recommendations in effectively and efficiently implementing the integration of three kinds of management systems.

\section{The International Standards}

\section{ISO 9001 Quality Management System}

The ISO 9000 standards describe a set of fundamental elements that enable the design and implementation of quality management system. The ISO 9000 series standards have their origins in the military procurement standards developed during the Second World War. They ultimately led to the publication of the first commercial quality management standard of BS 5750 by the British Standards Institute in 1979. In 1987, the British Standard of BS 5750 was adopted with a few changes as the international standard: ISO 9000 . The standard was updated in 1994 with some minor changes. The ISO 9000:1994 standards contain three auditable certification standards, i.e., ISO $9001 / 2 / 3$ (Tsim et al., 2002). They provide corresponding clauses for different type of business including companies that design their own products and services (20 clauses), companies that do everything except design (19 clauses), and companies where products and services can be verified only by inspection and test ( 16 clauses). Major changes were incorporated in the ISO 9000:2000 version. The latest ISO 9001:2000 revision is based on the following eight quality management principles: (i) customer-focused organizations; (ii) leadership; (iii) involvement of people; (iv) process approach; (v) system approach to management; (vi) continual improvement; (vii) factual approach to decision making; and (viii) mutually beneficial supplier relationships. Based on these eight guiding principles, the 20 clauses of the ISO 9001:1994 were revised into the following five main management requirements: (i) quality management system; (ii) management responsibility; (iii) resources management; (iv) product realization; and (v) measurement, analysis, and improvement (Zeng et al., 2005). The ISO $9001: 2000$ standard integrated the three standards into ISO 9001, which places emphasis on process management and resource management and has commonality of architecture with ISO 9004, so that quality assurance requirements and quality management can be aligned holistically.

\section{ISO 14001 Environmental Management System}

ISO 14000 is a series of standards and guidelines formulated in 1996 by the ISO with the aim of standardizing the environmental management programs of industries worldwide (Zeng et al., 2004). The ISO 14000 series comprise five aspects: environmental management system (EMS), environmental auditing (EA), environmental labeling (EL), environmental performance evaluation (EPE), and life cycle assessment (ECA). The standards can be classified into two types: guidance notes and specifications. All standards except ISO 14001 belong to the former. They are descriptive documents and not prescriptive requirements. Only ISO 14001 EMS is a standard. The core of the series is the ISO 14001 standard. Its adoption is voluntary. After adoption, an organization is to be audited. As a subset of ISO 14000, the EMS takes a systematic approach and provides a tool to enable organizations to control the impact of their activities, products, or services on the natural environment.

\section{OHSAS 18001 Safety Management System}

Occupational Health and Safety (OHS) management aims to create and maintain a safery working environment, while protecting and maintaining good health of the workers. OHSAS 18001 was firstly published in 1999 and has been developed to be compatible with standards of ISO 9001 and ISO 14001 management systems in order to facilitate the integrations of quality, environmental and occupational health and safery management systems in organizations. OHSAS 18001 supports and contributes to systematize an appropriate management of the risk incurred by the workers/employees/collaborators through good working conditions.

Although OHSAS 18001 does not set out specific OHS performance criteria, nor does it give detailed specifications for the design of a management system, it is applicable to any organization that wishes to establish an $\mathrm{OHS}$ management system to minimize risks to its employees and other interested parties; to implement, maintain, and continually improve an OHS management system; to assure itself of its conformance with its stated OHS policy; to demonstrate such conformance to others; to seek certification/registration of its OHS management system by an external organization; or to make a self-determination and declaration of conformance with the standard's specifications (Low \& Pong, 2003).

\section{Survey of Implementation and Barriers}

In order to properly design the questionnaire, the researchers interviewed senior managers of ten construction firms listed in the Dictionary of Certified Enterprises of China National Accreditation Board for Certifiers (CNAB, 2004), which covers all the construction firms obtained ISO 9001 certificate in China. The structured questionnaires were sent to 300 construction firms in China. Finally, 68 completed questionnaires were received with $22.7 \%$ of response rate.

Among the 68 contractors, 54 of them (79\%) are general contractors, and $14(21 \%)$ are subcontractors. All of the 68 responded firms are ISO 9000-certified, in which sixty responded construction firms (88\%) have implemented ISO 9000 standards for over three years. It revealed that most of the respondents have rich experience in the implementation of the standards.

Of the 68 respondents, twenty-four $(35 \%)$ were also ISO 14001 -certified. Thirty-seven (55\%) were going to implement the ISO 14001 standard in the near future. The other seven $(10 \%)$ are not planning to seek ISO 14001 certification if clients have no such requirements. All the respondents indicated that they have the knowledge on the ISO 14001 standard. In addition, only 5 firms $(7 \%)$ are certified for Occupational Health \& Safety. But $73 \%$ of the respondents claimed that they have understood the framework of health \& safety management system.

\section{Results and Analysis}

\section{Attitudes of Contractors towards IMS}

The respondents were asked to evaluate the necessity of integrating ISO 9001, ISO 14001 and OHSAS 18001 management systems. Of all the 68 contractors, 51 contractors (75\%) agreed the necessity of IMS. 12 contractors (18\%) opined that it was not necessary to integrate quality, environmental and occupational health and safety management systems. The others (7\%) have "no idea" in IMS. 
Table 1: Comparison between quality, environmental and occupational health \& safety management systems

\begin{tabular}{|c|c|c|c|}
\hline $\begin{array}{l}\text { Issues of management certification systems } \\
\text { affecting the role of organization }\end{array}$ & $\begin{array}{l}\text { ISO } \\
9001: 2000\end{array}$ & $\begin{array}{l}\text { ISO } \\
14001: 1996\end{array}$ & $\begin{array}{l}\text { OHSAS } \\
18001: 1999\end{array}$ \\
\hline To ensure compliance to exacting specifications & - & - & - \\
\hline The creation and adherence to main procedures & 0 & - & - \\
\hline $\begin{array}{l}\text { Process evaluation, monitoring, capability } \\
\text { assessment and improvements }\end{array}$ & - & - & $\circ$ \\
\hline $\begin{array}{l}\text { Defining and communicating operational } \\
\text { requirements and definitions }\end{array}$ & - & - & - \\
\hline $\begin{array}{l}\text { Performance measurement and evaluation including } \\
\text { audit and assessment }\end{array}$ & - & - & - \\
\hline Facilitating the health and safety of the workers & & ○ & - \\
\hline Facilitating health and safery of the community & $\circ$ & $\circ$ & - \\
\hline Contributing to the protection of the environment & & - & $\circ$ \\
\hline Identification and elimination of wastes & $\circ$ & - & $\circ$ \\
\hline A commitment to prevention of pollution & & - & $\circ$ \\
\hline Compliance to legislation and regulations & - & - & - \\
\hline
\end{tabular}

Notes: $\bullet$ = Defined requirement; $\bigcirc$ = Implied requirement; Source: Bamber et al. (2003).

In the 51 contractors supporting IMS, 23 contractors (45\%) respondents considered that IMS could "avoid duplication of procedures"; 18 contractors (35\%) think that an integrated system can "reduce the requirements for resources"; 8 (17\%) believe that IMS could "reduce conflict of procedures"; and $2(4 \%)$ chose "others".

Comparatively, the management systems standards of ISO 14001 (Environmental) and OHSAS 18001 (Occupational Health and Safety) are coupled with the standard ISO 9001 (Quality) for an organization (see Table 1).

Based on the similarity and compatibility of the three management systems, IMS has been extensively advocated. Low and Chin (2003) found that contractors in Singapore seem to support such integration. The benefits for IMS include an optimized management system, increased competitiveness, better utilization of resources, and so on. Wilkinson and Dale (2002) believed that integrating management systems has simplified the management of their business. Pun and Hui (2002) considered IMS can help companies foster a competitive edge. This is attributable to the minimization of financial loss, compliance with legislation, effective allocation of responsibilities, and promotion of community goodwill. Matias et al. (2002) explained the foreseen advantages of IMS for companies pertain to economies of scale in the certification processes and a joint approach to the provision of quality, environmental responsibility and workforce protection.

In addition, 12 contractors (18\%) thought IMS not necessary. All of them opined that separate quality, environmental and occupational health and safety management systems are different in some aspectsincluding: (i) different perceived customers and stakeholders: the customers for quality management system for contractors are clients; the customers for environmental management system are the general public, local communities, and the government; while the customers for occupational health and safety management are contractor's employees and workers on construction sites and other interested parties who may be exposed to health and safety risks associated with construction activities; (ii) interests concerning the environment are more homogeneous internally and externally than interests concerning product quality improvement. ISO 9001 provides a way of ensuring that construction products conform to specific requirements, but the ISO 14001 standard is concerned with the outcome of a contractor's activities and ensuring that it conforms to the environmental policy and objective. With regards to OHSAS 18001 standards, there is different attitudes between contractors and their employees and workers on construction sites. Undoubtedly the latter is more active than the former in implementing OHSAS 18001. That can be attributed to the fact that construction is one of the most hazardous industries.

\section{Barriers to Implementing IMS}

The respondents were required to explore the barriers in implementing IMS. The barriers in common include internal and external barriers. Internal barriers are obstacles that arise within the firms and prevent or impede IMS implementation or the adoption of IMS. The internal barriers are grouped as five categories:

- Human resources;

- Understanding and perception;

- Organizational structure;

- Company culture; and

- Others.

External barriers are obstacles that arise outside the firms and prevent or impede IMS implementation from the adoption of IMS. The external barriers are grouped as five categories:

- Certifying bodies;

- Stakeholder and customers;

- Institutional environment;

- Technical guidance; and

- Others. 
The results are shown in Table 2 .

Internal barriers to implementing IMS. From Table 2, it is shown that human rather than financial resources are the major barriers impeding IMS implementation. Lack of human resources and the multifunctional nature of staffbecomes ever-increasing importance not only to the implementation but also to the maintenance of IMS.

Traditionally, organizations have separate, competing staff groups to handle the different management systems. That easily results in conflicts of organizational structure. In addition, coordination from top leader to employees in first-line is very important in implementing IMS. The consciousness of top leader is very important for organizations to implement the standards. The leader must personally be involved in communicating the company's goals and plans and in motivating and rewarding the employees. Top management must be seen by the rest of the employees to be totally committed and involved. Top management support and commitment are thus essential for the integration process to be initiated, completed and subsequently maintained within the organizations. The managers consequently need to recognize that for the integrated system to be implemented and maintained, they must continuously push it forward.

Negative corporate attitudes towards IMS and an unfavorable company culture, often cited in organizations, conspire to create a climate that deprives the IMS implementation process of support. Organizational culture refers to the pattern of beliefs, values and learned ways of coping with experience that have developed during the course of an organizational history, and which tend to be manifested in its material arrangements and the behaviour of their members. Applied to organizations, climate can be said to be related to the prevailing atmosphere surrounding the organization, to the level of morale, and to the strength of feeling or belonging, care and goodwill among members. The extent to which employees accept the culture of the organization will have a significant effect on the climate. When quality and environmental management systems exist as two parallel systems in a company, the importance of quality and environmental management systems are focused respectively, that will result in cultural incompatibility in the organizations.

"Understanding and perception" is necessary to integrate two or more management systems. Analysis of existing systems should include the status of:

- Integration of systems needed to optimize performance.

- Standardization of document numbering needed to facilitate management system flow and navigation.

- Level of policy level documen-
Table 2: Barriers of implementing IMS

\begin{tabular}{|lll|}
\hline Scopes & Items & $\begin{array}{l}\text { Contractors } \\
\text { Responding (\%) }\end{array}$ \\
\hline Internal barriers & Human resources & $29(43)^{\prime}$ \\
& Organizational structure & $16(24)$ \\
& Company culture & $11(16)$ \\
& Understanding and perception & $7(10)$ \\
& Others & $5(7)$ \\
& Total & $68(100)$ \\
\hline \multirow{2}{*}{ External barriers } & Technical guidance & $28(41)$ \\
& Certifying bodies & $22(32)$ \\
& Stakeholder and customers & $11(16)$ \\
& Institutional environment & $7(11)$ \\
& Others & $0(0)$ \\
& Total & $68(100)$
\end{tabular}

Figures in brackets are percentages.

tation needed to ensure alignment with regulatory and corporate requirements.

- Gaps between existing documented programs and regulatory and corporate requirements.

- Use of administrative controls used to manage and control process safety management, risk management program, safety and health and environmental activities.

- Documents related to the same subject matter.

- Documents that are outdated.

- Documents no longer in use but still maintained in the management system.

- Accessibility of existing documentation.

Information gathered for the assessment should include:

- Process safety information (e.g. hazards, technology and equipment in the process).

- Organizational structure.

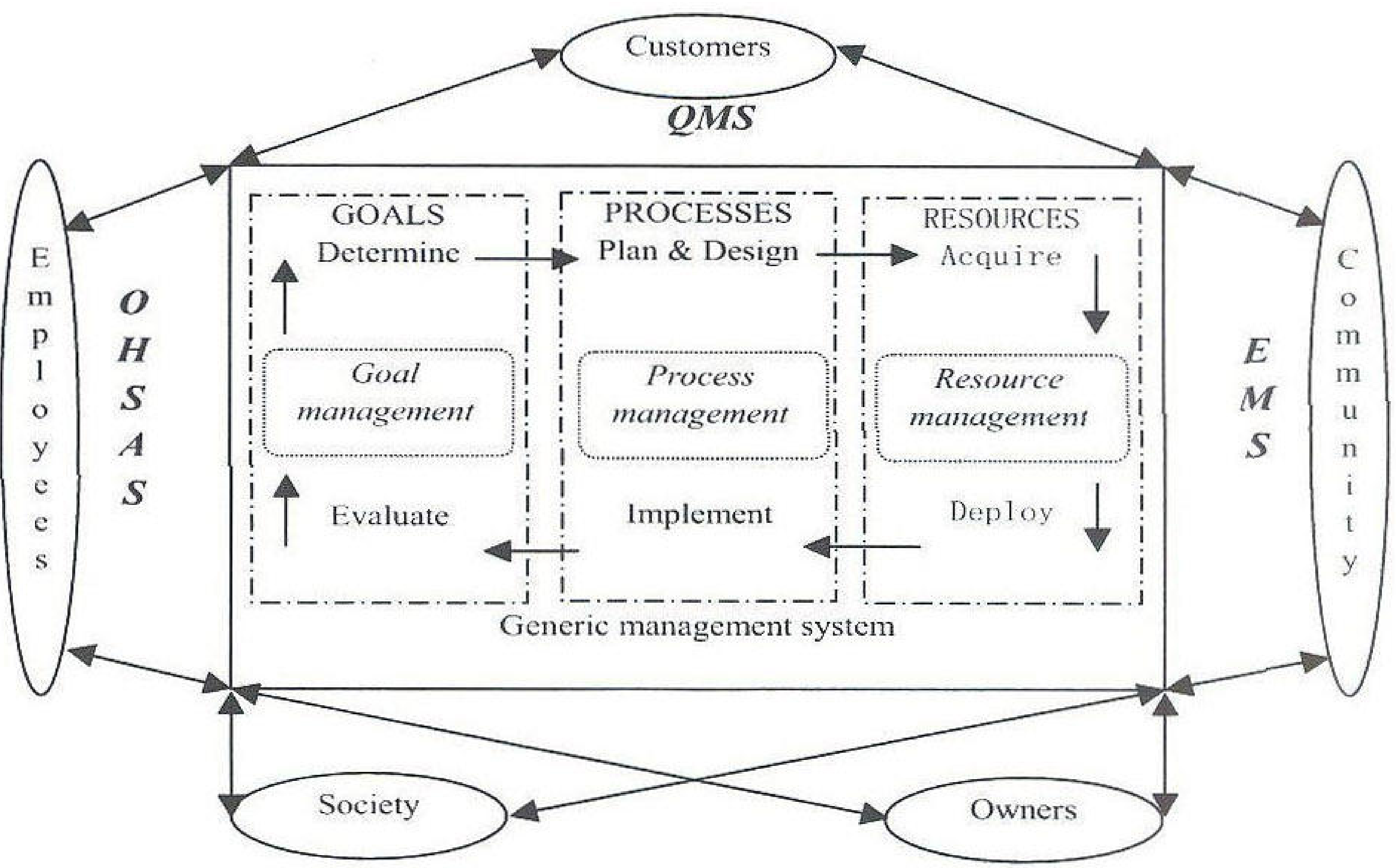

Figure 1: The systems model for IMS (Source: Karapetrovic \& Jonker, 2003). 
- Design codes and standards applied.

- Applicable regulatory requirements.

- Corporate and site process quality, safety, health and safety and environmental requirements.

- Formal/informal process overview and flow information.

- Other related processes (e.g. human resources, legal, etc.). After identifying the constraints inherent in the existing systems, the new design models can be developed and reviewed to facilitate:

- Optimizing management system performance.

- Standardizing document numbering and indexing.

- Eliminating redundancy and duplication of effort.

- Integrating all processes to include administrative controls.

Externalbarriers to implementing IMS. Of all the respondents, $41 \%$ recognized that the "Technical guidance" is the most important. In practice, the quality, environmental and occupational health and safety management systems are different in some aspects including: (i) different perceived customers and stakeholders, the customers for quality management system for contractors are clients; and (ii) interests concerning the environment are more homogeneous internally and externally than interests concerning product quality improvement. The difference creates the difficulties for contractors to develop systematic documentations. Contractors appear to need technical guidance, in particular for the environmental review and environmental aspects and significance evaluation, but experience problems gaining consistent quality information and experienced consultants of good quality. The lack of sector specific guidance and material tailored to different sizes of firms, especially very small firms, is a frequently referred to external barrier.

Additionally, 22 (32\%) contractors expect supports from certifying bodies. Currently quality management system (QMS) based on ISO 9001, environmental management system (EMS) based on ISO 14001 and occupational health and safety management system (OHSMS) based on OHSAS 18001 face certifications from three different certifying bodies. In practice, that causes difficulties for contractors to different certification and assessments. Hence, certifying bodies have to face the demand for conducting joint cerrifications.

Although the scope of quality, environmental and safety system audits is different, the procedure is almost identical. After identifying audit objectives and roles and responsibilities of all parties involved, the audit is initiated, the scope defined, and an

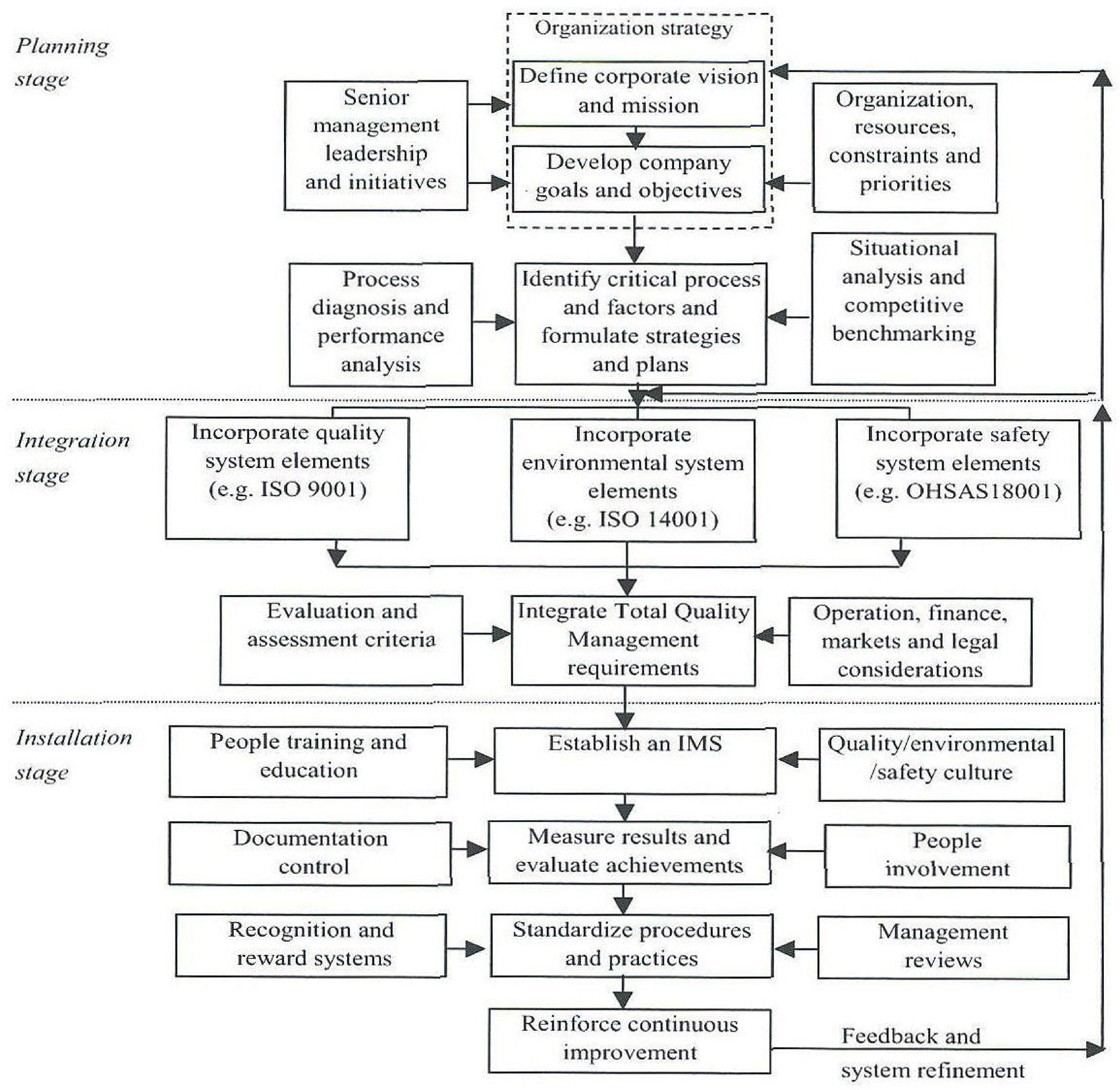

Figure 2: Model of three process stages for IMS 
audit plan is prepared. Subsequently, the auditor(s) or the audit team executes the audit, reports and records are submitted to the client, and appropriate follow-up actions are taken. Not to integrate them will certainly cause an unnecessary waste of resources and potential (Karapetrovic and Willborn, 1998).

Currently the International Organization for Standardization (ISO) makes efforts to develop a sound harmonized auditing system worldwide. Apart from the focus on overall system improvement, joint audit systems will bring cost savings, better allocation and deployment of human, material and information resources, as well as a unified problem solving approach that will increase efficiency and effectiveness of other interlinked systems.

\section{Approaches for IMS}

With respect to approaches for integration of management systems, $61 \%$ of the respondents claimed that "integration based processes" is suitable for them. The others have no ideas.

In recent years, researchers developed different approaches available for IMS, for example, "process model" (Pun \& Hui, 2002), "total quality model" (Bamber et al., 2004), and "systems model" (Karapetrovic \& Jonker, 2003). Karapetrovic and Jonker (2003) developed a systems model for IMS (see Figure 1).

The systems model for IMS contains five such ingredients: (i) determination of goals; (ii) planning and design of the system; (iii) acquisition and deployment of resources; (iv) system implementation; and (v) system evaluation and improvement. They are similar to the set of ingredients mentioned in the new ISO Guide 72 (2001) on management standard systems, which quotes policy, planning, implementation and operation, performance assessment, improvement and management review as core elements of any management system.

Pun and Hui (2002) proposed a process model of safety-focused quality management (SQM) based primarily on the TQM philosophy and the compliance requirements of ISO 9001 and OHSAS 18001:1999 standards. Based on the model, three process stages including planning, integration and installation are shown in Figure 2.

In the planning stage, it starts with the corporate vision and mission of an organization. Vision usually indicates where the organization wants to go and the mission tells everyone why a function is important to the organization. Safety/quality goals and objectives need to be clearly set, so that everyone is aware of the desired results.

In the integration stage, the organization needs to document the policies and procedures in combining quality management and safety management into a single system. In the installation stage, top management commitment, training and education, documentation control and audit are all governing the adoption of the system.

In general, each approach for integrating management system is with different advantages and disadvantages. It is evident that there is no 'one best approach' for every conceivable situation. For firms, the most important issue is to design a suitable and effective IMS based on its characteristics.

\section{Discussion}

The three sets of standards of ISO 9001 , ISO 14001 and OHSAS 18001 have a common underlying principle; continuous improvements based on Deming's cycle (Plan-Do-Check-Act). The three sets of standards share the same structure, and were composed on the basis of that cycle (Jonker and Karapetrovic, 2004). System documentation, records, policies, planning, responsibility, implementation, operational control, communication, verification, audits, conformity, continuous improvements and prevention are specific requirements that are common to all three standards (Karapetrovic \& Jonker, 2003). The objective of IMS is to achieve continuous improvements for contractor's performance.

To establish a framework for continuous improvement, the management system team should establish a formal means for all employees to communicate concerns, recommended ways to improve each program or process, and aspects of a given program or process that are not working. This can be done by establishing a manual directory for each program and using the organizations communication system to facilitate receiving and sending input and feedback from all employees. When a sufficient number of comments are gathered for a given document to warrant reconvening the work group, the work group can be reconvened and all comments need to be considered and resolved.

Administrative controls, established in the quality subsystem and integrated with all subsystems, can also help to administer and improve all programs. Continuous improvement is maintained by providing a means for all employees to identify non-conforming conditions needed to trigger corrective and preventive action, improving performance, achieving compliance requirements and applicable recommended practice.

For processes to continuously improve, an analysis of processes must be performed at various levels within the organization. To measure process variations relating to safety, environment and quality, management systems rely on process analysis and statistical process control techniques to provide the data required to make adjustments or improvements to processes that are not functioning to specified requirements.

Conversely, each process relies upon the management systems to facilitate changes required for each process to operate consistently and uniformly within specified requirements through incremental and breakthrough improvements and problem solving over time.

\section{Conclusions}

As more and more companies are implementing the ISO 9001 , ISO 14001 and OHSAS 18001 standards, they have been experienced the extra work and new challenge for implementing and running three separate systems. Integrated management systems (IMS) by combining quality (ISO 9001), environmental (ISO 14001) and occupational health and safery management (OHSAS $18001)$ provide an effective way to face the challenge.

Based on the results from a structured questionnaire survey administrated in this research, it is concluded that the construction industry welcome the idea of implementing integrated the ISO 9001 , ISO 14001 and OHSAS 18001 management systems.

In implementing IMS, the barriers result from internal and external barriers. The main internal barriers include: (i) human 
resources; (ii) organizational structure; (iii) company culture; and (iv) understanding and perception. The main external barriers include: (i) technical guidance; (ii) certifying bodies; (iii) stakeholder and customers; and (iv) institutional environment.

Although there is no 'one best approach' for every conceivable situation, the most important issue is to design a suitable and effective IMS based on its characteristics for contractors to achieve continuous improvements.

\section{References}

Bamber, C.J., Sharp, J.M., \& Castka, P. (2004). Third partyassessment: The role of the maintenance function in an integrated management systems, Journal of Quality in Maintenance Engineering, 10(1), 26-36.

China National Accreditation Board for Certifiers (CNAB). (2004). http://www.cnab.org.cn.

Chini, A.R., \& Valdez, H.E. (2003). ISO 9000 and the U.S. construction industry. Journal of Management in Engineering, 19(2), 78-82.

Jonker, J., \& Karapetrovic, S. (2004). Systems thinking for the integration of management systems. Business Process Management Journal, 10(6), 608-615.

Karapetrovic, S., \& Jonker, J. (2003). Integration of standardized management systems: search for a recipe and ingredients. Total Quality Management and Business Excellence, 14(4), 451-459.

Karapetrovic, S., \& Willborn, W. (1998). Integration of quality and environmental management systems. The TQM Magazine, 10(3), 204-213.

Low, S. P., Chin, P.Y. (2003). Integrating ISO 9001 and OHSAS 18001 for construction. Journal of Construction Engineering and Management, 129(3), 338-347.
Low, S.P., \& Pong, C.Y. (2003). Integrating ISO 9001 and OHSAS 18001 for construction.Journalof Construction Engineering and Management, $129(3), 338-347$.

Matias, J.C.D.O., \& Coelho, D.A. (2002). The integration of the standards systems of quality management, environmental management and occupational health and safery management. International Journal of Production Research, 40(15), 3857-3866.

Pun, K.F., \& Hui, I.K. (2002). Integrating the safery dimension into quality management systems: a process model. Total Quality Management, 13(3), 373-391.

Tsim, Y.C., Yeung, V.W.S., Leung, E.T.C. (2002). An adaptation to ISO 9001:2000 for certified organizations. Managerial Auditing Journal, $17(5), 245-250$.

Wilkinson, G., \& Dale, B.G. (1998) System integration: The views and activities of certification bodies. The TQM Magazine, 10(4), 288-292.

Wilkinson, G., \& Dale, B.G. (2002). An examination of the ISO $9001: 2000$ standard and its influence on the integration of management systems. Production Planning and Control, 13(3), 284-297.

Zeng, S.X., Tam, C.M., Deng, Z.M., \& Tam, Vivian W.Y. (2003). ISO 14000 and the construction industry. Journal of Management in Engineering, 19(3), 107-115.

Zeng, S.X., Tian, P., Tam, C.M., \& Tam, Vivian W.Y. (2004) Implementation of environmental management in the construction industry of China. Architectural Science Review, 47(1), 19-26.

Zeng, S.X., Tian, P., Tam, C.M., \& Tam, Vivian, W.Y. (2005). Evaluation of implementing ISO 9001: 2000 standard in the construction industry of China. Architectural Science Review, 48(1), 11-16. 